\title{
Uptake, Polymorphism, and the Construction of Networked Events on Twitter
}

\author{
Abstract \\ This study conceptualises networked events as a platform-oriented view of \\ media events by initiating a taxonomy of bottom-up construction. \\ Focusing on computer-mediated event construction that may involve live \\ delivery, permeate digital platforms, and attract user engagement prior to, \\ during, and after the occurrence of ceremonial or disruptive events, the \\ study argues that networked events can be characterised by \\ polymorphism - i.e., presence of distinct patterns of uptake and different \\ interactional orientations within the same space of interactions, such as \\ hashtags. Using a network dataset of 221,105 tweets that included the \\ hashtag \#HimToo which was used extensively during the US Senate \\ judiciary committee hearing that investigated claims of sexual harassment \\ against President Trump's Supreme Court nominee Brett Kavanaugh, the \\ study demonstrates that three types of construction-i.e., actor-centric, \\ memetic, and metaconstruction — causes polymorphism in Twitter \\ engagement related to the event.
}

Keywords: Media Events, Networked Events, Twitter, Social Network Analysis, Polymorphism 


\section{Introduction}

The notion of 'Media events' — grand occasions, such as contests of politics or sports, charismatic missions, and the rites of passage of the great that are televised as they take place, gathering attention universally and simultaneously (Dayan, 2010) — has been applied to describe the use of live broadcast content in many different contexts, such as grand wedding ceremonies (Dekavalla, 2012), mega sports events (Cui, 2013), organised public viewing (Widholm, 2016), hypermedia events (Kraidy, 2018), and moments of recognition in musical media events (Nærland, 2019). In Media Events, Dayan and Katz (1992) framed the concept as a television genre that interrupts normal flows of broadcasting as well as the daily routines of viewers, commanding attention to a 'ceremonial core'. As media are redefined in a culture of convergence which is characterised by flow of content across platforms (Jenkins, 2006) and switching between broadcast and social media is a routine (Vaccari, Chadwick, \& Loughlin, 2015), particularly during and after live events such as debates (Heo, Park, Kim, \& Park, 2016), scholarly work that explore the transformation of media events can provide useful insight. Sonnevend (2018) argues that Media Events (Dayan \& Katz, 1992) has been unfairly labelled a 'television book' due to the fact that the specific focus on live television limited its application across different types of media. Sonnevend argues that such application can be done without compromising its basic tenets. The current body of media events literature needs work that explore how digital media affordances configure event witnessing and construction. As Couldry and Hepp (2018) note, "what matters is to know whether and why 'media events' remain a 'live' concept for researching the broadest social and political consequences of media and communications infrastructures and institutions" (p.115). In a similar vein, Goldfarb (2018) notes, “[i]t leads me to wonder whether there is a digital equivalent of televisual media events to be found somewhere in the universe of Twitter or Facebook" (p.121). 
A platform oriented conception of media events can offer useful insight as Social Network Sites (SNS) offer new affordances that can amplify, record, and spread information and social acts (boyd, 2011) that may result in dramatic changes in the way events unfold on platforms. Klinger and Svensson (2015) argue that social media can be characterised by a distinct logic in which the network plays a crucial role in displaying content and determining attention received by users. A similar argument was made within the context of media events by (Frosh \& Pinchevski, 2018) who suggested that a new 'networked configuration' allows bottom-up witnessing of events. Platform-centric use of content where users engage with a range of different discourses as they appear in their social media feeds (Author removed, 2018) and the role played by ranking algorithms may also trigger personalised patterns of user experience related to media events. Such personalisation may jeopardise the 'ceremonial centre'- the core of the event that command attention. Events that permeate SNSs may take a more dynamic character as social media users exist in a state of 'connected presence' where continuous engagement is not necessary (Miller, 2008; Licoppe \& Smoreda, 2005) and different patterns of uptake triggered by user-generated content (Author removed, 2018) can affect the ways in which digital events are 'spread' and experienced. In this context, several questions deserve scholarly attention. How do media events occur on SNSs where the scope of events may transcend conventional 'live time' to 'connected time'? How can we theorize the user-driven transformative potential of SNSs in contexts of media events? In which ways do platform affordances allow novel and unique digital social phenomena within contexts of media events? While there is a wide range of work that examine social media use during broadcast and public events, how SNSs allow emergence of narratives that span beyond live delivery, as well as the role certain actors play in shaping such narratives (e.g., Dong, Liang, \& He, 2017; Heo et al., 2016; Poell, Abdulla, Rieder, Woltering, \& Zack, 2016; Ray, Brown, 
Fraistat, \& Summers, 2017), such work has not been adequately used to answer questions, such as the above, that emerge within the context of broadcast media studies.

This study aims to propose a conception of networked events as a platform-oriented view of events by initiating development of a taxonomy of user-driven bottom-up construction. A network analysis of \#HimToo - a Twitter hashtag that emerged in response to the US Senate judiciary committee hearing that investigated claims of sexual harassment against President Trump's Supreme Court nominee Brett Kavanaugh — is used to demonstrate that different types of construction results in diversity in terms of how users constructed and experienced the 'event' within the hashtag. It is argued that such internal diversity — defined as polymorphism in the following discussion - as a key characteristic of event construction that deviates from fundamental tenets of media events. From a more general viewpoint, the intention of this study is to compliment work that explain media events, rather than contradicting them, by demonstrating how analysis of patterns of social media user activity help theorise event witnessing.

The study is developed based on three basic premises. First, a digital equivalent of media events should not be strictly limited to 'live time' as users can extend the scope of events via live commentary, extended discussion, and production of new content related to the event. Second, there is a need for scholarly work that examine 'digitally native social phenomena'"patterns of interaction and expression that are born in the medium (i.e., the Internet) and can be different from offline communication" (Author removed, 2018, p.5). Third, a conception of events within the context of SNS should be a project of analysing digital traces as traceability of content is a distinct affordance of SNSs that allows mapping of event construction. 


\section{Networked Events}

Dayan and Katz's (1992) notion of media events conceptualised live broadcasting of historic occasions, such as the Olympics and the funeral of John F. Kennedy, as a genre which acknowledges the ability of broadcast media to "command attention universally and simultaneously" (p.1). Katz (1980) defined media events based on several characteristics: 1) events are broadcast live and not initiated by media although broadcast coverage is expected, 2) include an element of drama or ritual, 3) there is preplanning, 4) framed within time and space, and 5) personnel involved have high centrality. Dayan (2010) suggested that media events can be characterised by emphasis (i.e, omnipresence of transmitted events, disruption to organised schedules, live broadcasting, and repetition of shots), irrelevance of balance, neutrality, or objectivity, loyalty to the event definition suggested by organizers, and shared experience. Often actualised as contests, conquests, and coronations, media events were presented with reverence, ceremony, and respect and considered as efforts to redress conflict or restore order (Dayan, 2010). In general, media events stress the ability of broadcast media in gathering attention around a mediated centre. Dekavalla (2012) who examines the 2011 royal wedding in the UK from the perspective of media events, highlights the role played by the presenters, reporters, and interviewers in creating a script for what is being presented. She argues that while the televised coverage provided a narrative to viewers that they otherwise would not be able to access, this 'centre of power' was legitimised by incorporating footage of the public in the streets. This indicates that, although the public was included, construction of live events is still under professional control. From the audience point-of-view, loyalty to the dramaturgy of the event and its endorsement and relay was an important characteristic of media events (Dayan, 2010). Scholarly work that exemplify media events is rich and diverse. Criticisms related to the narrow focus on rituals and other typified scenarios and the problematic nature of viewing media events as genres have been documented (see Hepp \& 
Couldry, 2010; Hepp \& Krotz, 2008). While an extensive review of such work can offer useful insight, the purpose of this study is to argue for a platform-oriented explanation of event witnessing and construction.

An inquiry into the transforming nature of event witnessing needs to acknowledge that the interpretation of events has changed substantially with changes in media consumption as well as broad technological changes, such as the emergence and expansion of SNSs. Changes in the nature of occasions and issues that are broadcast live and changes in modes of delivery has resulted in substantial reinterpretation of media events. Dayan (2010), stresses that media events may provoke hostility and foster divide, as opposed to irenic sentiments based on which the original conception was developed. Dayan points out that the format of media events has dismantled and some of its elements have been absorbed by other genres. He also points to changes in pragmatics of media events. Katz and Liebes (2007) claim that they sense a "retreat from the genre of "media events"" and a rise in disruptive events (disaster marathons), such as live broadcasting of disaster, terror, and war (p.157). While ceremonial events were co-produced by broadcasters and organisers, disaster marathons were coproduced by perpetrators and broadcasters. This view also suggested that ceremonial events can be considered as establishment events as opposed to disruptive events that can be seen as threats to establishment. In a similar vein, Mihelj (2008) stresses the importance of shifting the focus from ceremonial events that support national unity to distressing events that may institute division among people. Some scholars argue that live programmes such as reality shows and musical programmes can be explained from the perspective of media events. Couldry (2002), for instance, suggests that Big Brother UK was constructed as a large-scale live event which was extended to the World Wide Web. Kyriakidou, Skey, and Mccurdy (2018) argue that the Eurovision Song Contest (ESC), as a global media event, constructed space for fans to experience cultural cosmopolitanism. The expansion of focus to include live 
content that may not be seen as 'grand' and ceremonial allowed applying this concept to understand media events across a range of live programmes.

While changes in the nature of media events has changed considerably, an even more dramatic change has taken place on the technological level. Katz and Liebes (2007) note that multiplication of channels, fierce competition, and ubiquity of mobile television equipment have "(1) scattered the audience and undermined the shared experience of broadcasting (2) taken the novelty out of live broadcasting, and (3) socialized us to "action" rather than ceremony, to a norm of interruption rather than schedule" (p.159). They also claim that increased cynicism has caused a decline in the centrality of media events. Sonnevend (2018) identifies the present-centric view, limitations in understanding narratives on a global level, and inattention to the ways in which events travel across platforms as limitations of the notion of media events. However, she argues that these technological views are misleading. In general, claims made by Katz and Liebes (2007) and Sonnevend (2018) resonate the fact that explaining media events as they permeate different types of media and platforms is a challenge faced by scholars. Couldry and Hepp (2018) explain the current media atmosphere further with a special emphasis on 'deep mediatization' - a social context characterised by the advanced spread of media through digitalisation, reliance on technological means of communication, and datafication (Hepp, Breiter, \& Hasebrink, 2017). Couldry and Hepp (2018) argue that an event such as the 2012 Olympics in the UK can only be understood by considering its construction across a variety of digital media. In particular, they highlight the role played by Twitter in the construction of the event along with mainstream media. In general, scholarly work that discuss the presence and the future of the notion of media events point to the complexity caused by the rise of online platforms and the need for scholarly work that explore 'digitally constructed events'. There is optimism regarding the ability of media events to explain events across platforms. For instance, Sonnevend (2018) notes that the main 
intellectual achievements of Dayan and Katz's (1992) theory are not bound to television and it is "relatively easy to expand Media Events backward (to radio) or forward (to digital media) without compromising its basic tenets" (p.124). Similarly, Couldry and Hepp (2018) claim that media events remains a live concept to examine social and political effects of communications infrastructure and institutions.

\section{Event Analysis as a Project of Tracing Uptake}

Hepp and Couldry's (2010, p.22) definition of media events, i.e., "certain situated, thickened, centering performances of mediated communication that are focused on a specific thematic core, cross different media products and reach a wide and diverse multiplicity of audiences and participants", situates media events across media platforms. This definition addresses several limitations of the concept, such as narrow focus on rituals or a given set of scenarios as it is based on fundamental properties of media events rather than types of events that can be used for characterisation. However, applicability of several fundamental tenets of the concept, such as the power held by the mediated core, loyalty to the event definition, and centrality of key personnel, should be tested in order to develop a platform-oriented conception of events. Such work should not be limited to strictly live sessions that require continuous presence of viewers/users. As Licoppe and Smoreda (2005) argue, new communication technologies allow users to construct a form of 'connected presence' where the boundary between absence and presence is blurry and communication consists of quasicontinuous exchanges. As opposed to broadcast media where continuous presence of audience is a required condition, new media allow users to maintain quasi-presence. Miller (2008) argued that connected presence can be seen in particular in microblogging sites such as Twitter. As connected presence characterises user interaction on SNSs over extended periods of time, work that theorise digitally constructed events should cover a broad range, taking user engagement prior to, during, and after live sessions into consideration. Within a 
context of connected presence, the 'build-up phase' is crucial for the development and contestation of event narratives (Robertson, 2018). Moreover, engagement after live delivery should also be considered as an essential phase of event construction on SNSs. Heo et al. (2016) demonstrate that TV viewers contribute to event experience via SNSs not only by opinion sharing and argumentation on a real-time basis, but also by contributing to the production and diffusion of the discourse. This suggests an emphasis on users as opposed to professional producers.

Bottom-up construction, as opposed to a top-down orchestration (Frosh and Pinchevski, 2018) can capture the essence of events that are experienced on SNSs. Accordingly, networked events can be defined as computer-mediated event witnessing and construction that may involve live delivery, permeate digital platforms, and attract user engagement prior to, during, and after the occurrence of ceremonial or disruptive events. Networked events can be conceptualised using three related notions: 1) affordances (Evans, Pearce, Vitak, \& Treem, 2017; Gibson, 1986), 2) uptake (Suthers et al., 2010), and 3) polymorphism in issue-response networks (Author removed, 2018). Gibson (1986) suggested that affordances or action possibilities are offered by a given environment and should be understood relative to the animal. Evans, Pearce, Vitak, and Treem (2017) define affordances as a relational structure between technology and user that can constrain or enable behavioural outcomes in a given context. This definition suggested that affordances are neither the object nor a feature of the object, not an outcome, and are variable. For instance, four types of affordances (i.e., persistence, replicability, scalability, and searchability) (boyd, 2011) show that online utterances are automatically recorded, archived, can be duplicated, highly visible, and accessible through search. As opposed to live broadcast content that is not easily searchable and accessible, users can search online content and engage with them. Moreover, such engagement can be enabled by affordances such as, metavoicing (i.e., reacting to others and 
content), triggered attending (i.e., engagement triggered by automated alerts), and networkinformed associating (i.e., conversation in a context of relational and content ties) (Majchrzak, Faraj, Kane, \& Azad, 2013). In general, the notion of affordances capture the action possibilities embedded in a given environment. Such possibilities relate to the design of the environment as well as user imaginations and expectations. Nagy and Neff (2015) explain that, user expectations may not be necessarily encoded into communication systems, but such expectations become part of what is available to them. They note that imagined affordances 'emerge between users' perceptions, attitudes, and expectations; between the materiality and functionality of technologies; and between the intentions and perceptions of designers" (p.5). This suggests that event construction on SNSs should be examined with an emphasis on how platform affordances result in certain types of engagement and acknowledgement of user expectations within digital environments. It also points to the fact that the scope of event analysis within connected presence should expand beyond conventional 'live limits'. Such connected presence is traceable as Application Programming Interfaces (APIs) allow obtaining digital trace data. Therefore, examining networked events is both a project of mapping digital traces over longer periods as well as acknowledging the role played by the network - i.e., follower-followed relationships - in content production and dissemination.

While individuals representing media organizations and event organisers is central to broadcast media events (Dayan, 2010; Dekavalla, 2012), user-driven construction of networked events is enabled by the fact that platforms afford uptake activity. Uptake is "the relationship present when a participant's coordination takes aspects of prior or ongoing events as having relevance for an ongoing activity" (Suthers, Dwyer, Medina, \& Vatrapu, 2010, p.9). For instance, a reply in a threaded discussion shows that the user selects a particular message as relevant for participation. For instance, as Twitter updates can be 
considered as part of event construction (Couldry \& Hepp, 2018), uptake activity on Twitter can provide a basis to trace such construction. Author removed (2018) identify an original tweet as projected uptake that contains potential for uptake (e.g., possible ‘@replies' or retweets) and a retweet as actual uptake. Accordingly, networked events constructed on Twitter include a series of projected and actual uptake activity. This is a crucial element of event construction that differentiates networked events from its broadcast counterpart as a mediated centre may not necessarily sustain beyond live time on SNS as users construct networked events via uptake and the relevance of content for uptake may vary across different user groups. Similarly, actor centrality may not sustain over extended periods of time on SNSs. As previous work has demonstrated, analysis of uptake structures offer a relational perspective of how specific interactions are embedded in broader networks (see Suthers, 2006; Suthers \& Desiato, 2012).

From a macroscopic point-of-view, work that conceptualise a digital equivalent of media events requires demonstrating whether or not networked events can sustain what Couldry and Hepp (2018) call a 'centre' constructed through managed output of media institutions. As Frosh and Pinchevski (2018) argue, a networked configuration cannot be associated with a single perspective and the 'centre' of the event is highly dynamic due to spreading and dissemination of information. Despite the significance of this claim, there is a lack of empirical work that establish this claim on empirical grounds. While the above discussion points to the importance of empirical analysis of digital traces, it is also important to develop theoretical explanations that can characterise the dynamic nature of such interaction. This study aims to explicate the notion of polymorphism - co-existence of different forms of collective phenomena (Author removed, 2018) - to explain the dynamic nature of the bottom-up construction of events. Uptake-driven construction and the possibility of polymorphism within SNSs may jeopardise the 'ceremonial centre' of media events. This 
may happen as users have different motivations for information sharing on online platforms. This is particularly the case with viral information sharing which results from large numbers of users taking up specific messages for sharing. Berger and Milkman (2012) show that content-related factors, such as psychological arousal, can cause virality. Conversely, userrelated factors, such as motivation (Picone, De Wolf, \& Robijt, 2016) and viral behavioural intent (Alhabash \& McAlister, 2015), can play a role in viral information sharing. Nahon and Hemsley (2013) stress that virality can result from characteristics of information (e.g., novelty, resonance, humour) as well as factors such as common topical interest. As a range of factors trigger uptake on SNSs, the 'live centre' of media events may shift. The following discussion demonstrates that polymorphism can be used as a conceptual basis to describe and empirically demonstrate shifts in focus within networked events. It is argued that actorcentric, memetic, and meta construction result in polymorphism in events constructed via Twitter hashtags.

\section{Deviations from Basic Tenets of Media Events: Polymorphism in Networked Events}

The study of contemporary media events relates to the question of which digital traces are left and the extent to which they construct media events (Couldry \& Hepp, 2018). As social media affordances, such as Twitter hashtags, allow mapping traces of actual and projected uptake on SNSs (e.g., Author removed, 2018), they can be used as entry points for examining polymorphism within networked events. Polymorphism is the "condition of occurring in several different forms" ("Polymorphism," n.d.). Singh (2001, p.1507) defines polymorphism as "presence in the same population of two or more alternative forms of a distinct phenotype such as flower colour." Similarly, Hedrick's (2006) work on genetic polymorphism show that heterozygotes have a greater resistance to malaria than homozygotes. Lu, Liu, and Yan (2019, p.1908) describe crystalline polymorphism as "the presence of multiple packing and aggregate architectures of the same molecular system." In general, polymorphism can be 
characterised by variation in a given attribute within the same category. Although applied widely in fields such as biology (e.g., Iarmarcovai, Bonassi, Botta, Baan, \& Orsie, 2008), polymorphism has rarely been used to explain social phenomena. Examining differences among user clusters within Twitter hashtags, Author removed (2018) describe polymorphism as structures consisting of diverse collective phenomena within mediated spaces such as hashtags. This work demonstrates that user groups with different interactional orientations can co-exist within technologically-enabled moments of connectedness. For the purpose of this study, polymorphism is defined as the presence of distinct patterns of uptake and different interactional orientations within the same network of interactions, such as the diversity of interactions in issue-response networks (Author removed, 2018) and ad-hoc publics such as \#HimToo (Author removed, 2019). Within the context of networked events, polymorphism can indicate the absence of or shifts in a dominating 'mediated core' as well as changes in actor centrality. Polymorphism is both a structural and a phenomenological notion. While network structures can demonstrate structural polymorphism, diversity in user expectations, imaginations and orientations provide evidence of the phenomenological aspect of this concept. Pop polyvocality (Milner, 2013), a similar notion, embraces the ability of participatory media to allow a multivocal and vibrant public discourse. Milner demonstrates that polyvocal participation allows members of mediated publics to make nuanced commentary, draw on a range of topics, and share perspectives on important issues. The following section demonstrates that user engagement related to networked events is polymorphic as activity can concentrate around specific actors and/or messages and factors such as memetic construction and ideological polarisation may structure such engagement.

Social media activity associated with events such as the live hearing on claims of sexual harassment against President Trump's Supreme Court nominee Brett Kavanaugh can be considered as media events due to intense media involvement as well as the social media 
engagement. Although the event was not as dramatic or intense as a grand ceremony or a disaster marathon, such as war or natural disaster, that Katz and Liebes (2007) identified as more established genres in mainstream television. The hearing can be seen as a thematic core which, based on Hepp and Couldry's (2010) definition, was central to the media as well as social media narratives that emerged. The 'broadcast centre' of the event was the live hearing on the $27^{\text {th }}$ of September, 2018. Phillips (2018) reported that "besides the 21 senators, Kavanaugh, Ford, a handful of journalists and a very, very small slice of the public, the rest of us will be watching this on television." From a conventional media events perspective, the live hearing can be seen as an event in which the broadcast audience does not play a significant role in the construction of the narrative. Social media activity, such as the Twitter hashtag \#HimToo that emerged in response to the Kavannaugh hearing constitute networked uptake activity related to the event. The following discussion provides evidence of polymorphism within \#HimToo at two different periods that includes the time of the live hearing as well as activity that emerged afterwards (Period 1: from September 25 to October 10, Period 2: from October 9 to 12). Figure 1 provides a combined timeline that shows the activity level for each period.

Social Network Analysis (SNA) offers a relational perspective to understand social phenomena and, as a method, it is based on the premise that social life is created by relations and patterns of such relations (Marin \& Wellman, 2010). SNA is widely used to map social media engagement (e.g., Gruzd, Wellman, \& Takhteyev, 2011; Ichau, Frissen, \& d'Haenens, 2019; Rathnayake \& Suthers, 2018). In SNA, a network is depicted using a set of nodes and ties (edges) among them (Marin \& Wellman, 2010) network. Identification of cohesive subgraphs, commonly known as 'community detection', is used to identify groups of actors that connected with each other than others within networks (Suthers, 2017). 
Figure 1: Twitter Activity Before and After the Hearing

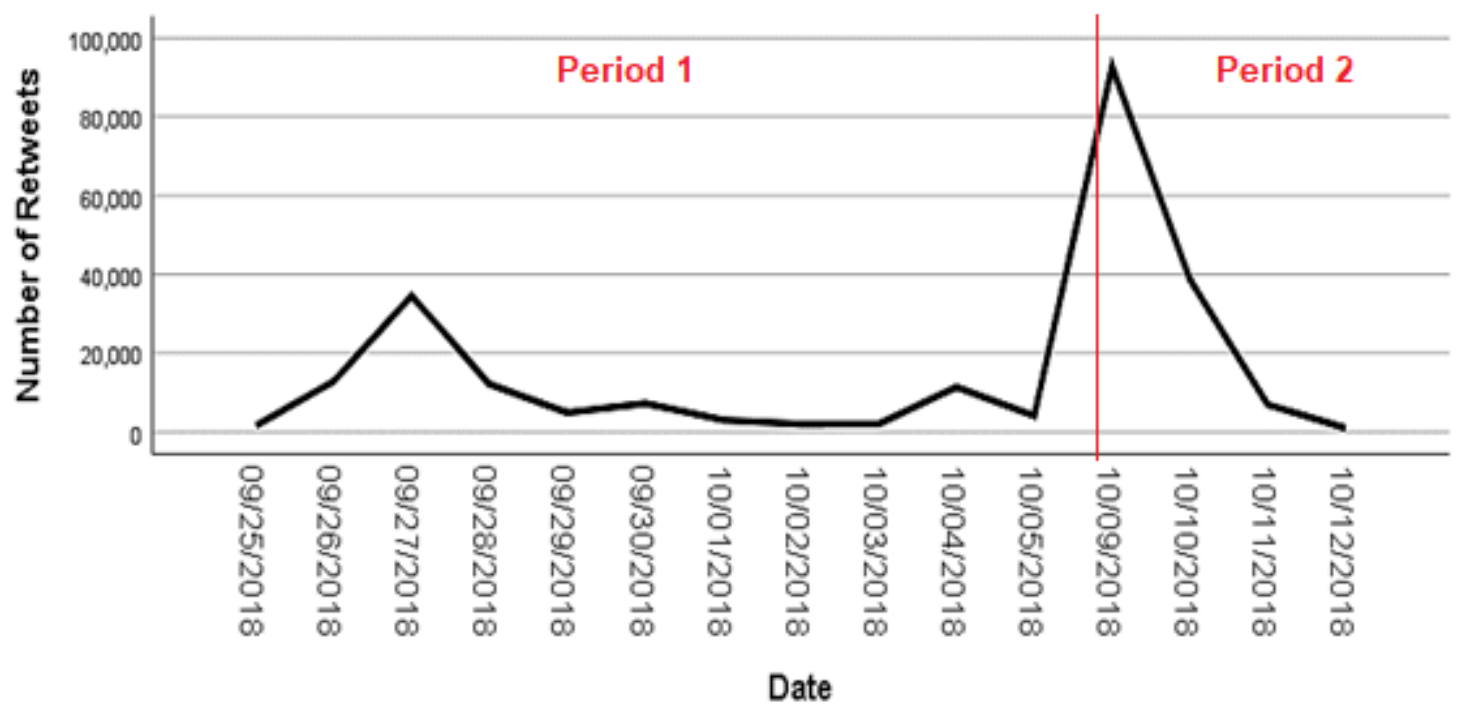

Retweet networks representing two crucial periods were created to map uptake patterns within \#HimToo. These networks included Twitter users (nodes) and retweeting activity (edges) for each period. Duplicate edges, and tweets send by users whose Twitter names represented languages other than English were removed from analysis. Degree values were calculated to examine the extent with certain actors command attention within the network. These degree values are also indicate indegree (number of incoming edges per node) as the networks included only retweets. Partitions (communities) within retweet networks were identified by using the community detection algorithm developed by Blondel, Guillaume, Lambiotte, and Lefebvre (2008). Community detection allows examining how activity is concentrated around actors and fragmented into partitions (communities). The modularity statistic calculated in the community detection process indicates the extent to which the network constitutes a cohesive 'community' (a score close to one indicates high fragmentation while a score close to zero indicates low fragmentation). This is an appropriate measure to examine whether networked events gather engagement around key actors or messages that hold its centre. Actor centrality was assessed by examining the degree values (i.e., number of edges for each node). The following discussion presents the results of 
network analysis and argues that internal diversity, defined as polymorphism, can be identified as a key characteristic of networked events. Such diversity reflects three types of construction within \#HimToo.

\section{Actor-Centric Construction}

Figure 2(a) (top) shows the \#HimToo retweet network covering the period from $25^{\text {th }}$ of September to $5^{\text {th }}$ of October 2018. This retweet network included 83,530 acts of retweeting (represented by edges) by 55,562 users (represented by nodes). A modularity value of 0.521 indicated that the \#HimToo retweet network was not highly fragmented. Results also showed that there are 483 communities (clusters) in the network. However, the majority of retweets (51.9\% nodes) were in the largest cluster which was formed by users taking up tweets sent by the conservative political figure Candace Owens. Figure 2(b) shows the partition lead by Candace Owens (degree: 35,044$)$ who is represented by the white colour node in the center. Degree values of top ten actors given in Table 1 show that Candace Owens has a consderibly higher degree value $(35,044)$ than the next top actor (degree: 3,549). This indicates that Owens is the most central actor in this network. As shown in the frequency distribution of nodes across clusters (Figure 2(c)- bottom right), while the partition lead by Candace Owens attracted more than $50 \%$ of users in the network, the rest of the activty was scattered across 482 small clusters. Table 2 provides the number of Twitter users in top ten partitions for each period. 
Figure 2: \#HimToo Retweet Network (From $25^{\text {th }}$ of September to $5^{\text {th }}$ of October 2018)

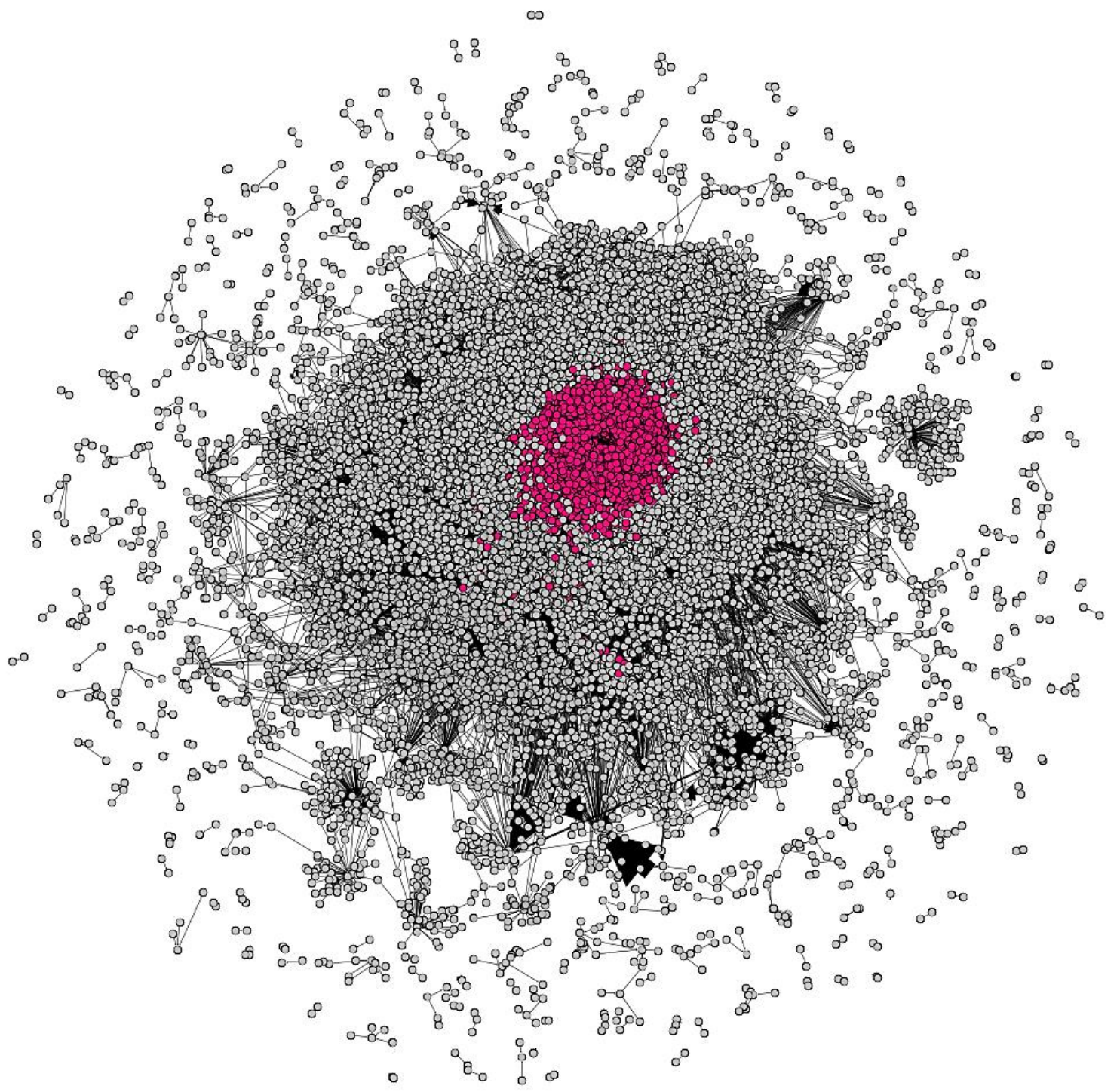

(a) Full retweet network

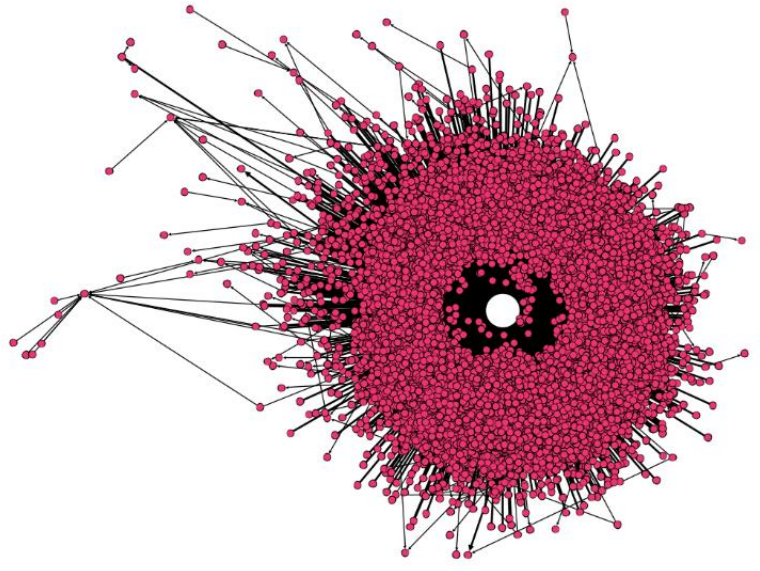

(b) Partition lead by Candace Owens

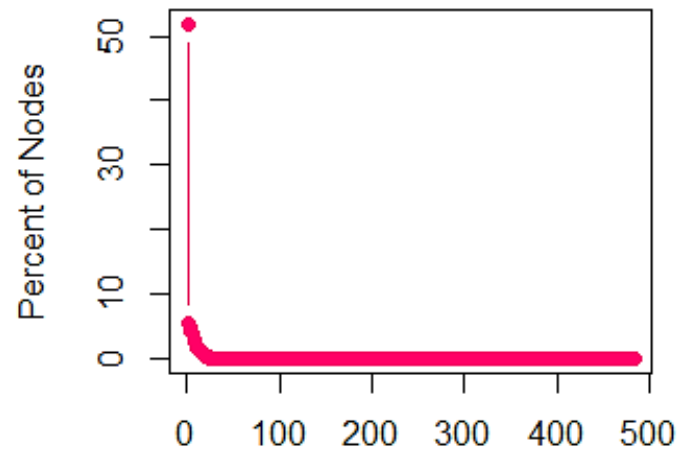

Partition Label

(c) Distribution of nodes among partitions

Note: Visualisation on the top shows the full network that includes 55562 nodes and 83530 edges, visualised using OpenOrd Layout Algorithm. Visualisation on the bottom shows the largest partion in the network. Node that received the highest uptake (@RealCandaceO) is coloured in white 
Table 1: Top Actors and Degree Values

\begin{tabular}{|l|l|l|}
\hline Duration & Twitter Handle & Degree \\
\hline Period 1 & @ RealCandaceO & 35044 \\
\cline { 2 - 3 } & @ ShemekaMichelle & 3549 \\
\cline { 2 - 3 } & @SiddonsDan & 2153 \\
\cline { 2 - 3 } & @ 1776HotLips & 2039 \\
\cline { 2 - 3 } & @ kimusastrong & 1600 \\
\cline { 2 - 3 } & @Education4Libs & 1483 \\
\cline { 2 - 3 } & @ LauraLoomer & 1131 \\
\cline { 2 - 3 } & @ LindaSuhler & 1056 \\
\cline { 2 - 3 } & @ hrenee80 & 874 \\
\cline { 2 - 3 } & @My2CentsGritXO & 726 \\
\hline Period 2 & @ amandawallwin & 31967 \\
\cline { 2 - 3 } & @SJGrunewald & 14897 \\
\cline { 2 - 3 } & @PrisonPlanet & 12694 \\
\cline { 2 - 3 } & @ BritniDWrites & 5610 \\
\cline { 2 - 3 } & @TheTweetOfGod & 4461 \\
\cline { 2 - 3 } & @MikeDrucker & 3479 \\
\hline & @ sweet_emmee & 2389 \\
\hline & @ Jonf1979 & 2356 \\
\hline & @ tonyposnanski & 2041 \\
\hline & @living_marble & 1975 \\
\hline
\end{tabular}

Author removed (2019) argue that, in \#HimToo, Owens attempts to attract a like-minded audience using an affective address and the activity in the the cluster (Figure $2 \mathrm{~b}$ ) indicates conservative orientation of engagement. From a networked events persepctive, concetration of the majority of activity around Owens and the absence of other dominating partitions within the network indicates an actor-centric core. References to the live hearing which Owens included in her tweets (e.g., "Kavanaugh has me on the brink of tears. The determination of this hearing is so much bigger than people realize.") and the use of other sociotechnical markers, such as \#ConfirmKavanaugh, directs the attention of users in this cluster towards the thematic core- i.e., the hearing. This actor-centric concentration of uptake is significantly different from a conventional model of media events for at least two reasons. First, content is neither institutionallly produced nor presented by media professionals.

Second, users take up messages for retweeting rather than media personnel choosing content 
for publishing. Dominance of Candance Owens indicates that centers of power can emerge within networked events. This is a 'constructed' centre as users make a decision when they choose Owens's message for uptake. This observation is consistent with the argument made by Poell et al. (2016) who challenged the idea that social media protest and communication is primarily driven by self-motivation. Poell and colleagues observed a distinct form of social media leadership characterised by mediation, translation, and channeling of user feedback related to contentious politics accomplished by inviting and steering user participation, as opposed to commanding and proclaiming. As mentioned before, the above analysis covers the period between $25^{\text {th }}$ of September and $5^{\text {th }}$ of October, 2018. However, further changes in activity in \#HimToo, as described in the following section, presented a more complicated networked event.

\section{Memetic Construction}

In order to examine \#HimToo over a longer period of time, a second retweet network (Figure 3a) covering four days from $9^{\text {th }}$ to 12 th of October was constructed. This network included 113,013 nodes and 137,575 edges and had a modularity value of 0.768 (1390 communities). Higher modularity compared to the first period indicated that \#HimToo had further fragmented into smaller communities. However, the results showed that this network included several large partitions as opposed to the previous network that had only one large partition (Figure 2b). Figure 3(c) shows the distribution of nodes across partitions. Table 2 provides frequencies and percentages of nodes included in the ten largest partitions. From a structural point of view, a network (or a cluster within a network) that has a central actor takes a hub-and-spoke structure. Such a structure was clearly evident in the leading partition during the period between $25^{\text {th }}$ of September to $5^{\text {th }}$ of October 2018 (Figure 2b). Networks characterised by the multiplicity of leading actors tend to have a decentralised structure. It

was evident that one of the top four partitions in the \#HimToo network (between $9^{\text {th }}$ and $12^{\text {th }}$ 
October) had such a structure (Figure 3b). Upon further investigation, it was found that this partition included a range of satirical memes that shifted the focus of retweeting activity away from the Kavannaugh hearing. This wave of satirical memes was triggered by a tweet sent by a user, a mother, on the $6^{\text {th }}$ of October that expressed concern about her son being afraid of false allegations ("This is MY son, He graduated \#1 in boot camp. He was awarded the USO award. He was \#1 in A school. He is a gentleman who respects women. He won't go on solo dates due to the current climate of false sexual accusations by radical feminists with an axe to grind. I VOTE. \#HimToo.”). The tweet escalated a wave of satirical tweets despite the fact that the son created a Twitter handle named '@Thatwasmyom' to react to his mother's tweet mentioning that he will never support \#HimToo (see Author removed, 2019). This backlash included tweets containing user-generated satirical memes that mimicked mother's tweet (See Figure 4 for examples).

Author removed (2019) argue that the satirical meme that started spreading within \#HimToo had limitations from a feminist perspective, as each mutation seems to be to render the mom's tweet ridiculous and are not consistently connected to gender related violence. Moreover, the meme was not directly connected to the live hearing. The decentralised nature of this cluster shows how memetic exchange can cause polymorphism within networked events. Memetic construction — creation and uptake of different 'mutations' of usergenerated memes related to an event— may trigger shifts in the focus of networked events. This is allowed by platform affordances that enable users to uptake different versions of a meme and share it with their follower networks. Coined by Richard Dawkins (1976) in which he used the term to describe the propagation of genetic material, the notion of memes has permeated the social realm, especially characterising the Internet culture where trendy pictures, videos, and variants of content, such as iterations, parody, and satire, spread rapidly (Marwick, 2013). Wiggins and Bowers (2014) explain that recursive production, 
consumption, and reproduction can characterise virtual physicality of memes in digital culture. Similarly, Shifman (2013) identifies dissemination from person to person, imitation and mimicry, and diffusion through competition and selection as the main attributes of memes.

Presence of a network partition formed around different mutations of a meme demonstrates structural differences in uptake activity within \#HimToo. Memes created and disseminated within networked events that form decentralised clusters may distance themselves from the original event. The cluster constructed through memes (Figure 3(b)) has a decentralised structure as opposed to the cluster lead by Candace Owens (Figure 1(b)). This shows that community level retweeting activity within a networked event can consist of both hub-andspoke as well as decentralised uptake structures. In other words, differences between the two clusters reflect structural polymophism within the networked event. Moreover, differences in user intention (i.e., political engagement versus satire) indicate polimorphism from the perspective of interactional orientation. This observation contradicts with the conventional conception of media events for several reasons. First, as mentioned previously, users, rather than media professionals as demonstrated by (Dekavalla, 2012), create and select information in these clusters for uptake. Second, imitation and mimicry suggest that information disseminated through friendship networks are subject to change as they spread. In this case, users engage in the active production of memes. Satirical memes that emerged in response to the conservative mother's tweet directed attention away from the thematic core as opposed to some other memes, such as the meme that ridiculed Kavannaugh's references to beer (see Figure 5), that directed users towards the original event. Third, spreading different mutations of the meme results in decentralised patterns of information consumption, rather than gathering users around a key actor or message. 
Figure 3: \#HimToo Retweet Network (From $9^{\text {th }}$ to 12 th of October)

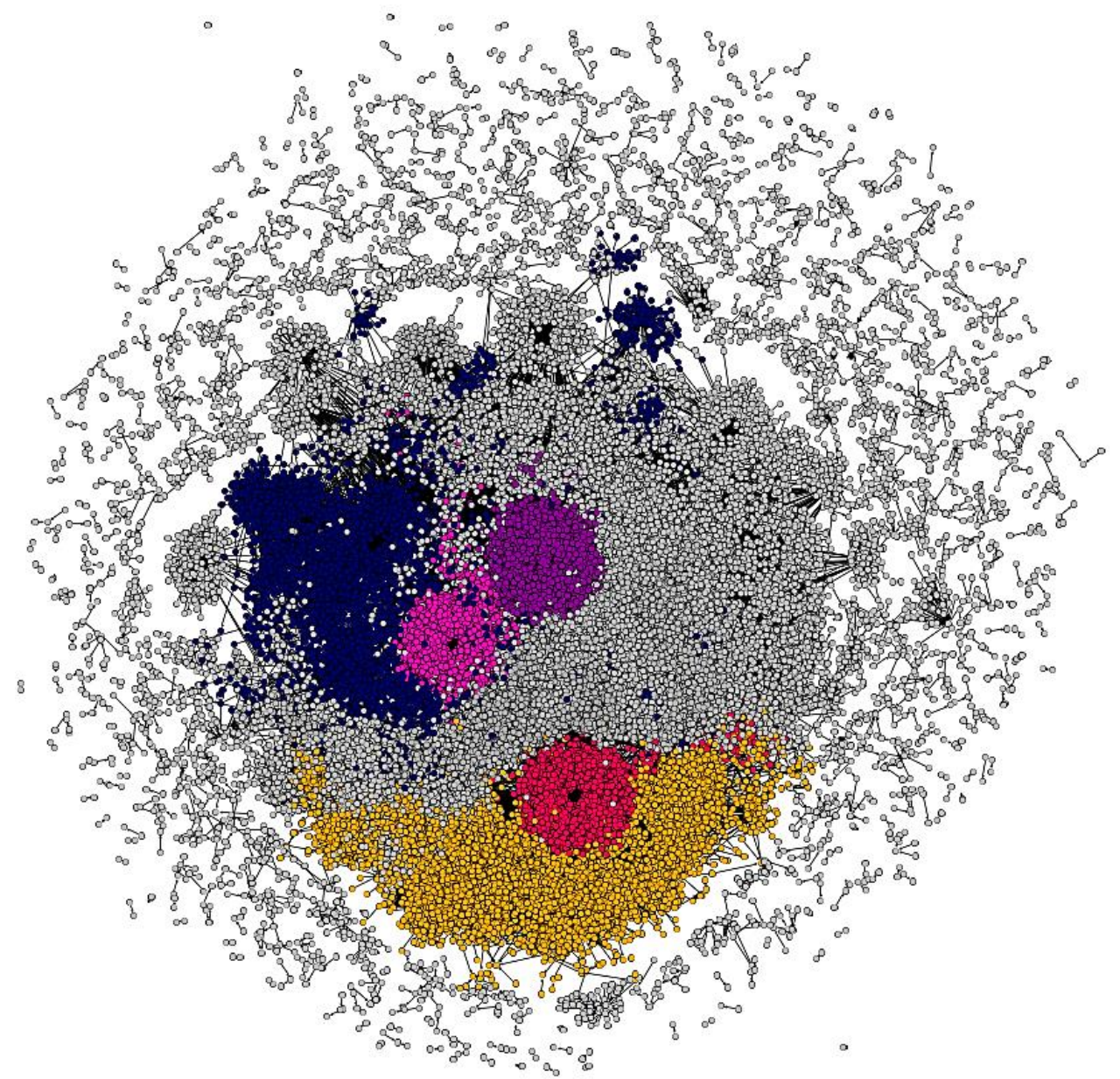

(a) Full retweet network
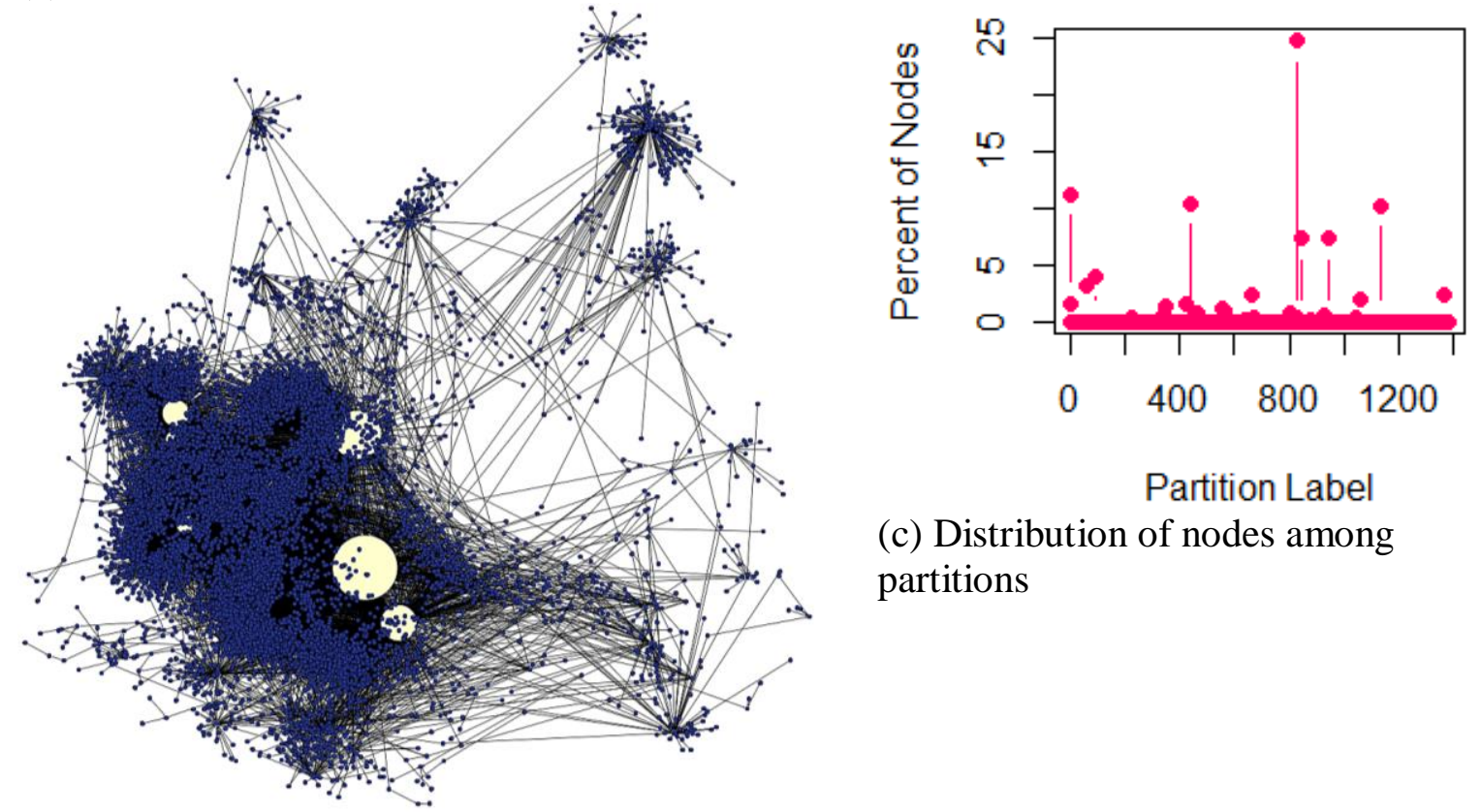

Partition Label

(c) Distribution of nodes among partitions

(b) Partition containing satirical memes

Note: The full network includes 113013 nodes and 137575 edges. Visualised using OpenOrd Layout algorithm 
Table 2: Number of Actors/Twitter Users in Top Ten Modularity Partitions

\begin{tabular}{|l|l|l|l|l|l|l|l|}
\hline Period 1 \\
$\begin{array}{l}\text { Partition } \\
\text { Number }\end{array}$ & $\begin{array}{l}\text { Number } \\
\text { of Nodes }\end{array}$ & Percent & $\begin{array}{l}\text { Cumulative } \\
\text { Percent }\end{array}$ & $\begin{array}{l}\text { Partition } \\
\text { Number }\end{array}$ & $\begin{array}{l}\text { Number } \\
\text { of Nodes }\end{array}$ & Percent & $\begin{array}{l}\text { Cumulative } \\
\text { Percent }\end{array}$ \\
\hline 0 & 28932.00 & 52.07 & 52.07 & 3 & 27920 & 24.7 & 24.71 \\
\hline 112 & 3193.00 & 5.75 & 57.82 & 1279 & 12668 & 11.2 & 35.91 \\
\hline 192 & 2823.00 & 5.08 & 62.90 & 157 & 11744 & 10.4 & 46.31 \\
\hline 106 & 2445.00 & 4.40 & 67.30 & 96 & 10534 & 9.3 & 55.63 \\
\hline 4 & 2206.00 & 3.97 & 71.27 & 154 & 8418 & 7.4 & 63.08 \\
\hline 6 & 2112.00 & 3.80 & 75.07 & 57 & 8066 & 7.1 & 70.21 \\
\hline 274 & 2084.00 & 3.75 & 78.82 & 693 & 4557 & 4.0 & 74.25 \\
\hline 125 & 1686.00 & 3.03 & 81.86 & 472 & 3539 & 3.1 & 77.38 \\
\hline 361 & 1222.00 & 2.20 & 84.06 & 555 & 2429 & 2.1 & 79.53 \\
\hline 399 & 1048.00 & 1.89 & 85.94 & 167 & 2408 & 2.1 & 81.66 \\
\hline
\end{tabular}

Figure 4: 'Mutations' of the 'This is my son' Meme in \#HimToo

This is My son, Michael. He had to be institutionalized because of a simple misunderstanding with his sister Judith and therefore did not get to go to A school. He is afraid to date women in today's current climate because he will probably kill them. \#HimToo

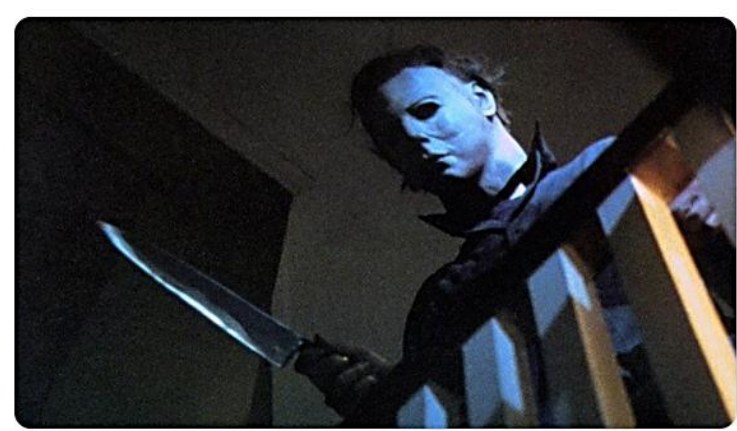

7:34 AM · Oct 9, $2018 \cdot$ Twitter Web Client
This is my son. He was \#1 on the charts. He won't go on solo dates even though he never gave up, let you down, run around, or deserted you, make you cry, say goodbye, tell a lie nor hurt you \#HimToo

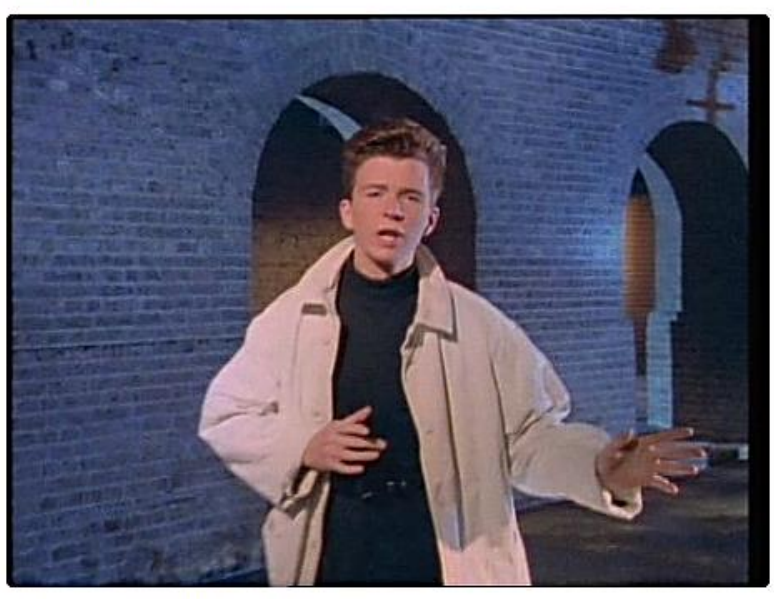

O 17.3K 11:54 PM - Oct 8, 2018 
Figure 5: Example for a Brett Kavannaugh Beer Meme

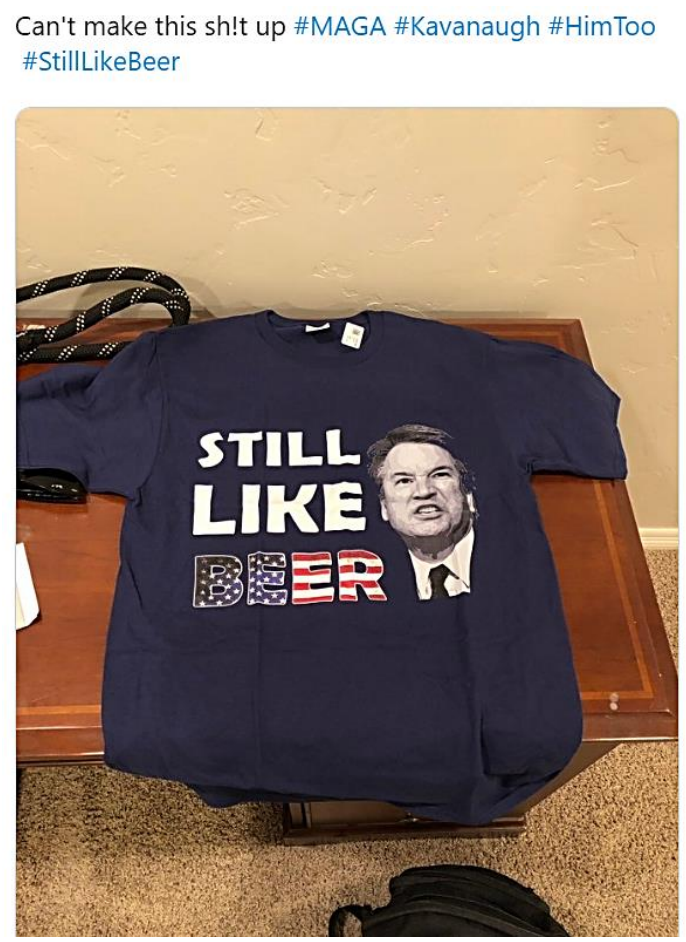

\section{Metaconstruction}

A third distinct wave of retweets included in the network for the second period attempted to repurpose the hashtag. Such attempts can be called metaconstruction as they redefine the purpose of the space within which they operate. Metaconstruction- user-driven redefining of computer-mediated spaces, such as hashtags- was evident in two large partitions in the second retweet network. One of those partitions (31967 nodes, $24.71 \%$ of the full retweet network) (Figure 6a) contained the message "the real \#HimToo is that men are more likely to be sexually assaulted than falsely accused." The other partition (12664 nodes, $11.21 \%$ of the full network) (Figure 6d) included a comparison of the above mentioned tweet sent by the Kavannaugh supporting mother and her son's reaction and included the comment "sometimes Twitter can be amazing". Top actors in both these partitions had high centrality (see Table 1) and Candace Owens was not included in the list of top ten actors. This showed that Candace Owens 'dominance within the hashtag had decreased substantially in the second period, at least in the largest partitions. 
Figure 6: \#HimToo Partitions Containing Metaconstruction

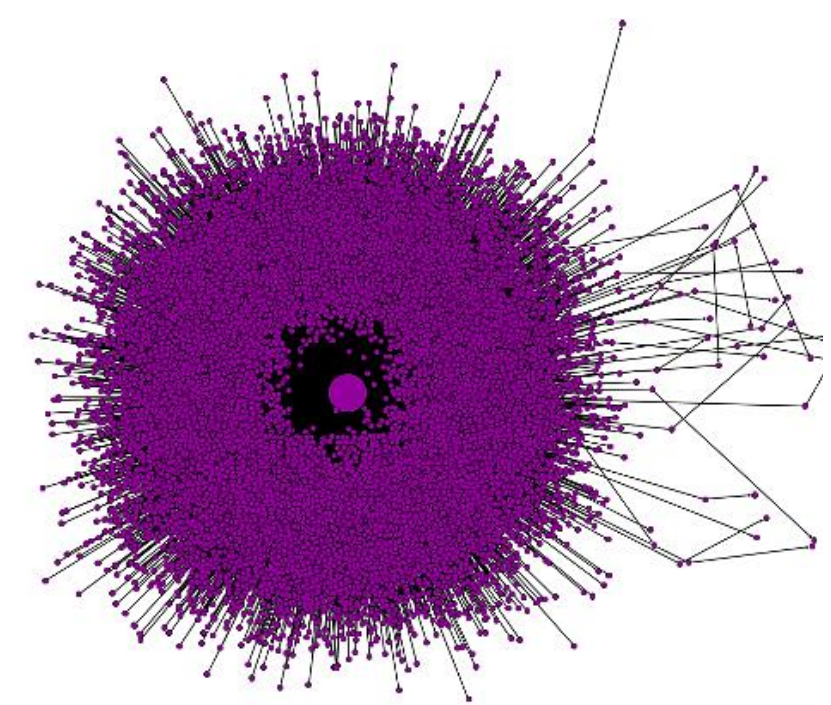

(a) Partition 1 (network 2)

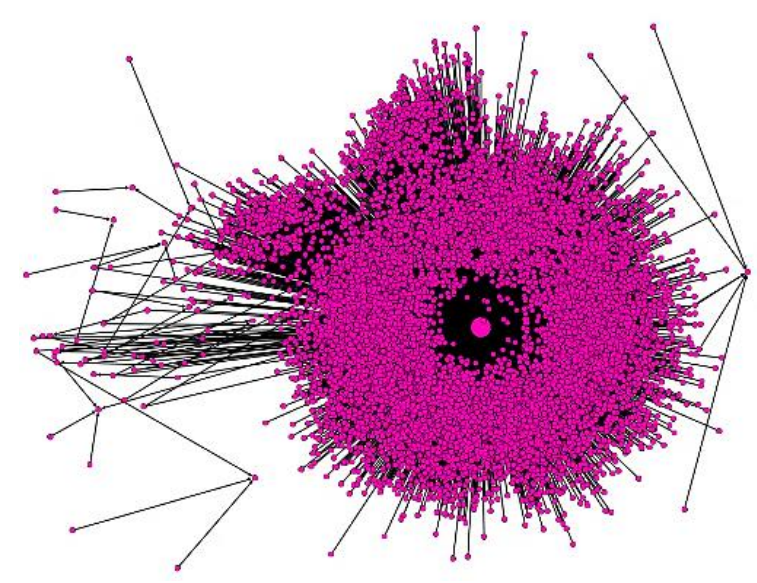

(c) Partition 2 (network 2)

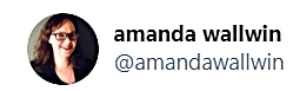

The real \#HimToo is that men are more likely to sexually assaulted than falsely accused.

2:31 am $\cdot 9$ Oct $2018 \cdot$ Tweetbot for iOS

(b) The most retweeted message in partition 1 in network 2

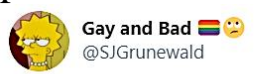

Sometimes Twitter is amazing.

\#MeToo $\$$ \#HimToo \#IBelieveSurvivors
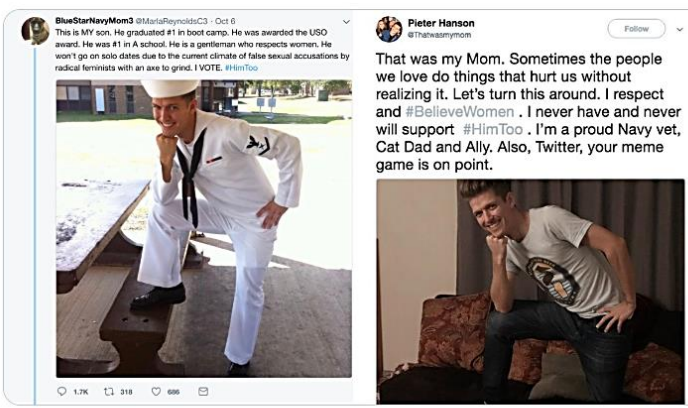

6:13 am · 9 Oct 2018 - Twitter Web Client

(d) The most retweeted message in partition 2 in network 2

While the first partition mentioned above clearly redirects the hashtag, arguably away from the Kavannaugh hearing, the second message is a reference to the platform itself. This shows that while conventional media events are characterised by a clear power difference between media professionals and members of the audience where the direction of the event is controlled by event organisers and media institutions, networked events allow users to repurpose the event. In other words, loyalty to the event definition is not a necessary 
condition in the bottom-up construction. This is enabled by the malleability of networked spaces, such as hashtags. Arguably, metaconstruction is an outcome of imagined affordances (Nagy \& Neff, 2015) of digital platforms as the ability to redefine a mediated space, such as a hashtag, results from the technical elements that allow hashtag functionality as well as user intention to redefine the space.

\section{Conclusion}

This study answers calls for scholarly work that conceptualise how media events unfold on SNSs (Couldry \& Hepp, 2018; Goldfarb, 2018). Couldry (2002, p.286) claims that "[t]he liveness of an event does not require that every element of it be broadcast live, but rather the belief that, taken together, the media consumption provide shared, but privileged access to the event as it unfolds." In a similar vein, construction of networked events does not require that social media users are aware of or is exposed to all the utterances related to the event, yet events are constructed in 'connected presence' via acts of projected and actual uptake, especially within digital spaces, such as hashtags, afforded by platforms. Hashtags, as sociotechnical markers afford concentration of activity around a thematic event, the Brett Kavannaugh hearings in this case. There is unity within networked events as activity is organised around such a specific event. However, the scope of networked events are not limited strictly to a broadcast or professionally constructed centre,- i.e., a centre consisting of managed output of media institutions (Couldry \& Hepp, 2018)- as user-generated content and uptake of which may trigger tangential activity on SNSs. Elements of digital culture, such as

memes, may result in such network events, creating micro-level digital centres that can attract uptake. Co-existence of actor-centric, memetic, and meta construction within the same hashtag indicated internal polymorphism within the event. From this perspective, and within the limits of the current study, networked events can be seen as consistent with polymorphic moments of connectedness (Author removed, 2018). 
The above characterisation of networked events differ from Dayan and Katz's (1992) original conception of media events as well as previous work that applied the original concept as a template. Polymorphism as reflected in the shifting focus of reweeting activity shows that loyalty to the event definition- a central property of media events (Dayan, 2010)- does not necessarily characterise networked events. This argument is consistent with Frosh and Pinchevski's (2018) claim that bottom-up events have fluctuating centres consisting of social media feeds, such as posts, tweets, and images. Although twitter activity within \#HimToo was related to the Kavanaugh hearing, differences in focus across partitions indicates that Twitter users do not construct the networked event strictly within the scope of the the main event. As mentioned previously, this relates to another fundamental difference between media events and network events i.e. while media event narratives are professionally constructed (Dekavalla, 2012), networked events constructed by social media users may not have a consistent narrative. This results from digital media affordances that allow users to imagine various types of engagement. This argument is consistent with the observation that (Heo et al., 2016) not only do viewers interpret broadcast events, but also they actively contribute to sustain the discourse.

Given above differences, the conception proposed in this study should not be seen as an application of media events within the context of SNS. Rather, as Sonnevend (2018) suggested, the present study needs to be considered as an effort to initiate development of a digital equivalent of media events. As the main characteristic of networked events - i.e., polymorpishm - contradicts with the conventional definition of media events, the current study should be seen as a conceptualisation of what Frosh and Pinchevski's (2018, p.136) call a post-media events configuration - "radically different relations between media and event than that which characterized broadcasting". The definition of networked events suggested here, however, does not strictly contradict with Hepp and Couldry's (2010) view of media 
events as certain situated, thickened, centering performances as the hashtag \#HimToo rendered crowds into an ad hoc public organised around the hearing. However, this public is not as strictly situated or centred as in conventional media events due to internal polymorphism. As polymorphism captures diversity in interaction, networked events is not subject to limitations of media events, such as the specific focus on rituals, viewing events as genres, or the narrowness of typified events identified by Hepp and Couldry (2010). Polymorphism also embraces the fact that engagement may differ across events. Therefore, it is possible that different community structures as well as participatory practices, such as the centrality of social media influencers, may characterise other events.

While the main purpose of the study is to present a conceptualisation of events that unfold on SNSs, it has implications beyond media or networked events. Polymorphism, which has been observed in other issue-response networks (Author removed, 2018), can serve as a generalizable notion that can capture the essence of online interaction. The plurality of public engagement acknowledge by this concept is consistent with previous studies that discuss different ways in which such plurality manifests, such as polyvolcality in online engagement (Milner, 2013), divergent discourse on digital platforms (e.g., Gallagher, Reagan, Danforth, \& Dodds, 2018) as well as political polarization (Himelboim, McCreery, \& Smith, 2013; Rathnayake \& Suthers, 2018). As projected or actual uptake can be present in every social media post, polymorphism may exist across issues and platforms. Accordingly, future work may develop polymorphism into a general theory of interaction on online platforms. Accordingly, explication of polymorphism and initiating a taxonomy related to its manifestation is the main contribution made by this study. While the current study provides evidence of internal diversity, future work may examine external polymorphism across issues, hashtags, and platforms. 


\section{References}

Alhabash, S., \& McAlister, A. R. (2015). Redefining virality in less broad strokes: Predicting viral behavioral intentions from motivations and uses of Facebook and Twitter. New Media and Society, 17(8), 1317-1339. https://doi.org/10.1177/1461444814523726

Berger, J., \& Milkman, K. L. (2012). What makes online content viral? Journal of Marketing Research, 49(2), 192-205. https://doi.org/10.1509/jmr.10.0353

boyd, danah. (2011). Social Network Sites as networked publics: Affordances, dynamics, and implications. In Z. Papacharissi (Ed.), A networked self: Identity, community, and culture on social network sites (pp. 39-58). New York and London: Routledge Taylor \& Francis Group. https://doi.org/10.4324/9780203876527

Boyle, K., \& Rathnayake, C. (2019). \#HimToo and the networking of misogyny in the age of \#MeToo. Feminist Media Studies, 1-20.

Couldry, N. (2002). Playing for celebrity: Big Brother as ritual event. Telematics and Informatics, 3(3), 283-293.

Couldry, N., \& Hepp, A. (2018). The continuing lure of the mediated centre in times of deep mediatization : Media Events and its enduring legacy, (2004). https://doi.org/10.1177/0163443717726009

Cui, X. I. (2013). Media events are still alive: The opening ceremony of the Beijing Olympics as a media ritual. International Journal of Communication, 7, 1220-1235.

Dawkins, R. (1976). The selfish gene. Oxford: Oxford University Press, USA.

Dayan, D. (2010). Beyond media events: Disenchantment, derailment, disruption. In Media Events in a Global Age (pp. 23-31). London, New York: Routledge Taylor \& Francis Group. 
Dayan, D., \& Katz, E. (1992). Media events: Live broadcasting of history. Cambridge: Harvard University Press.

Dekavalla, M. (2012). Constructing the public at the royal wedding. Media, Culture \& Society, 34(3), 296-311. https://doi.org/10.1177/0163443711433665

Dong, T., Liang, C., \& He, X. (2017). Social media and internet public events. Telematics and Informatics, 34(3), 726-739. https://doi.org/10.1016/j.tele.2016.05.024

Evans, S. K., Pearce, K. E., Vitak, J., \& Treem, J. W. (2017). Explicating affordances: A conceptual framework for understanding affordances in communication research. Journal of Computer-Mediated Communication, 22(1), 35-52. https://doi.org/10.1111/jcc4.12180

Frosh, P., \& Pinchevski, A. (2018). Media and events after Media Events. Media, Culture and Society, 40(1), 135-138. https://doi.org/10.1177/0163443717726007

Gallagher, R. J., Reagan, A. J., Danforth, C. M., \& Dodds, P. S. (2018). Divergent discourse between protests and counter-protests: \#BlackLivesMatter and \#AllLivesMatter. PLoS ONE, 13(4), 1-23. https://doi.org/10.1371/journal.pone.0195644

Gibson, J. J. (1986). The theory of affordances. The Ecological Approach to Visual Perception. London: Lawrence Erlbaum Associates.

Goldfarb, J. C. (2018). Media events, solidarity, and the rise and fall of the public sphere. Media, Culture \& Society, 40(1), 118-121. https://doi.org/10.1177/0163443717726010

Gruzd, A., Wellman, B., \& Takhteyev, Y. (2011). Imagining Twitter as an imagined community. American Behavioral Scientist, 55(10), 1294-1318. https://doi.org/10.1177/0002764211409378

Hedrick, P. W. (2006). Genetic polymorphism in heterogeneous environments: The age of 
genomics. Annual Review of Ecology, Evolution, and Systematics, 37, 67-93. https://doi.org/10.1146/annurev.ecolsys.37.091305.110132

Heo, Y. C., Park, J. Y., Kim, J. Y., \& Park, H. W. (2016). The emerging viewertariat in South Korea: The Seoul mayoral TV debate on Twitter, Facebook, and blogs. Telematics and Informatics, 33(2), 570-583. https://doi.org/10.1016/j.tele.2015.08.003

Hepp, A., Breiter, A., \& Hasebrink, U. (2017). Rethinking transforming communications: An introduction. In A. Hepp, A. Breiter, \& U. Hasebrink (Eds.), Communicative Figurations: Transforming Communications in Times of Deep Mediatization (pp. 3-13). Palgrave Macmillan.

Hepp, A., \& Couldry, N. (2010). Introduction: Media events in globalized media cultures. In Media Events in a Global Age (Couldry, N, pp. 1-38). Abingdon: Routledge.

Hepp, A., \& Krotz, F. (2008). Media events, globalization and cultural change: An introduction to the special issue. Communication, 33, 265-272. https://doi.org/10.1515/COMM.2008.017

Himelboim, I., McCreery, S., \& Smith, M. (2013). Birds of a feather tweet together: Integrating network and content analyses to examine cross-ideology exposure on Twitter. Journal of Computer-Mediated Communication, 18(2), 40-60. https://doi.org/10.1111/jcc4.12001

Iarmarcovai, G., Bonassi, S., Botta, A., Baan, R. A., \& Orsie, T. (2008). Genetic polymorphisms and micronucleus formation: A review of the literature. Mutation Research, 658, 215-233. https://doi.org/10.1016/j.mrrev.2007.10.001

Ichau, E., Frissen, T., \& d'Haenens, L. (2019). From \#selfie to \#edgy. Hashtag networks and images associated with the hashtag \#jews on Instagram. Telematics and Informatics, 
44(April), 101275. https://doi.org/10.1016/j.tele.2019.101275

Jenkins, H. (2006). Convergence culture: Where old and new media collide. New York and London: New York University Press.

Katz, E. (1980). Media events: The sense of occasion. Studies in Visual Communication, 6(3), 84-89.

Katz, E., \& Liebes, T. (2007). ' No More Peace !': How Disaster, Terror and War Have Upstaged Media Events University of Pennsylvania. Journal of Communication, l(March 2005), 157-166.

Klinger, U., \& Svensson, J. (2015). The emergence of network media logic in political communication: A theoretical approach. New Media \& Society, 17(8), 1241-1257. https://doi.org/10.1177/1461444814522952

Kraidy, M. M. (2018). Temporality: Hypermedia events in the age of Islamic state. Television \& New Media, 19(2), 170-176. https://doi.org/10.1177/1527476417697197

Kyriakidou, M., Skey, M., \& Mccurdy, P. (2018). Media events and cosmopolitan fandom: ‘ Playful nationalism ' in the Eurovision Song Contest. International Journal of Cultural Studies, 21(6), 603-618. https://doi.org/10.1177/1367877917720238

Licoppe, C., \& Smoreda, Z. (2005). Are social networks technologically embedded? How networks are changing today with changes in communication technology. Social Networks, 27, 317-335. https://doi.org/10.1016/j.socnet.2004.11.001

Lu, B., Liu, S., \& Yan, D. (2019). Recent advances in photofunctional polymorphs of molecular materials. Chinese Chemical Letters, 30, 1908-1922. https://doi.org/10.1016/j.cclet.2019.09.012

Majchrzak, A., Faraj, S., Kane, G. C., \& Azad, B. (2013). The contradictory influence of 
social media affordances on online communal knowledge sharing. Journal of ComputerMediated Communication, 19(1), 38-55. https://doi.org/10.1111/jcc4.12030

Marin, A., \& Wellman, B. (2010). Social network analysis: An introduction. Handbook of Social Network Analysis, 22. https://doi.org/10.1176/appi.ajp.162.12.2384

Marwick, A. (2013). Memes. Contexts, 12(4), 12-13.

https://doi.org/10.1177/1536504213511210

Mihelj, S. (2008). National media events: From displays of unity to enactments of division. Cultural Studies, 11(4), 471-488.

Miller, V. (2008). New media, networking and phatic culture. Convergence: The International Journal of Research into New Media Technologies, 14(4), 387-400. https://doi.org/10.1177/1354856508094659

Milner, R. M. (2013). Pop polyvocality: Internet memes, public participation, and the Occupy Wall Street movement. International Journal of Communication, 7, 2357-2390.

Nærland, T. U. (2019). Altogether now ? Symbolic recognition, musical media events and the forging of civic bonds among minority youth in Norway. European Journal of Cultural Studies, 22(1), 78-94. https://doi.org/10.1177/1367549417719013

Nagy, P., \& Neff, G. (2015). Imagined Affordance: Reconstructing a Keyword for Communication Theory. Social Media and Society, 1(2). https://doi.org/10.1177/2056305115603385

Nahon, K., \& Hemsley, J. (2013). Going Viral. Cambridge, UK: Polity Press.

Phillips, A. (2018, September). A viewer's guide to the Kavanuagh hearing. The Washington Post. 
Picone, I., De Wolf, R., \& Robijt, S. (2016). Who Shares What with Whom and Why? Digital Journalism, 4(7), 921-932. https://doi.org/10.1080/21670811.2016.1168708

Poell, T., Abdulla, R., Rieder, B., Woltering, R., \& Zack, L. (2016). Protest leadership in the age of social media. Information Communication and Society, 19(7), 994-1014. https://doi.org/10.1080/1369118X.2015.1088049

Polymorphism. (n.d.). In Oxford Dictionaries.

Rathnayake, C., \& Suthers, D. D. (2018a). 'Enclaves of exposure': A conceptual viewpoint to explore cross-ideology exposure on social network sites. Social Science Journal. https://doi.org/10.1016/j.soscij.2018.08.015

Rathnayake, C., \& Suthers, D. D. (2018b). Twitter Issue Response Hashtags as Affordances for Momentary Connectedness. Social Media and Society, 4(3). https://doi.org/10.1177/2056305118784780

Ray, R., Brown, M., Fraistat, N., \& Summers, E. (2017). Ferguson and the death of Michael Brown on Twitter: \#BlackLivesMatter, \#TCOT, and the evolution of collective identities. Ethnic and Racial Studies, 40(11), 1797-1813. https://doi.org/10.1080/01419870.2017.1335422

Robertson, C. (2018). The media event build-up phase : A site of contestation and counternarratives. International Journal of Communication, 12, 3207-3226.

Shifman, L. (2013). Memes in a digital world: reconciling with a conceptual troublemaker. Journal of Computer-Mediated Communication, 18, 362-377. https://doi.org/10.1111/jcc4.12013

Singh, R. S. (2001). Polymorphism. In Encyclopedia of Genetics (p. 1507). 
https://doi.org/10.1006/rwgn.2001.1012

Sonnevend, J. (2018). The lasting charm of Media Events. Media, Culture \& Society, 40(1), 122-126. https://doi.org/10.1177/0163443717726013

Suthers, D. (2017). Applications of cohesive subgraph detection algorithms to analyzing socio- technical networks. In Proceedings of the 50th Hawaii International Conference on System Sciences (pp. 2128-2137). Hawai'i: Institute of Electrical and Electronics Engineers, Inc. (IEEE).

Suthers, D. D. (2006). A qualitative analysis of collaborative knowledge construction through shared representations. Research and Practice in Technology Enhanced Learning, 1(2), $1-28$.

Suthers, D. D., \& Desiato, C. (2012). Exposing chat features through analysis of uptake. In 45th Hawaii International Conference on System Sciences (pp. 3368-3377). IEEE. https://doi.org/10.1109/HICSS.2012.274

Suthers, D. D., Dwyer, N., Medina, R., \& Vatrapu, R. (2010). A framework for conceptualizing, representing, and analyzing distributed interaction. International Journal of Computer-Supported Collaborative Learning, 5(1), 5-42. https://doi.org/10.1007/s11412-009-9081-9

Vaccari, C., Chadwick, A., \& Loughlin, B. O. (2015). Dual screening the political: Media events , social media , and citizen engagement. Journal of Communication, 65, 10411061. https://doi.org/10.1111/jcom. 12187

Widholm, A. (2016). The sociality of public space broadcasting during media events. Convergence: The International Journal of Research into New Media Technologies, 22(6), 581-595. https://doi.org/10.1177/1354856515586041 
Wiggins, B. E., \& Bowers, G. B. (2014). Memes as genre: A structurational analysis of the memescape. New Media \& Society, 17(11), 1886-1906.

https://doi.org/10.1177/1461444814535194 